\title{
Beneficial Effect of Tempol, a Membrane-Permeable Radical Scavenger, on Inflammation and Osteoarthritis in In Vitro Models
}

\author{
Giovanna Calabrese ${ }^{\dagger}\left(\mathbb{D}\right.$, Alessio Ardizzone ${ }^{\dagger}$, Michela Campolo, Sabrina Conoci, Emanuela Esposito *(i) \\ and Irene Paterniti
}

Citation: Calabrese, G.; Ardizzone,

A.; Campolo, M.; Conoci, S.; Esposito,

E.; Paterniti, I. Beneficial Effect of

Tempol, a Membrane-Permeable Radical Scavenger, on Inflammation and Osteoarthritis in In Vitro Models. Biomolecules 2021, 11, 352. https:// doi.org/10.3390/biom11030352

Academic Editor: Monika Herten

Received: 29 January 2021

Accepted: 22 February 2021

Published: 25 February 2021

Publisher's Note: MDPI stays neutral with regard to jurisdictional claims in published maps and institutional affiliations.

Copyright: (c) 2021 by the authors. Licensee MDPI, Basel, Switzerland. This article is an open access article distributed under the terms and conditions of the Creative Commons Attribution (CC BY) license (https:// creativecommons.org/licenses/by/ $4.0 /)$.
Department of Chemical, Biological, Pharmaceutical and Environmental Sciences, University of Messina, Viale Ferdinando Stagno D’Alcontres, 31-98166 Messina, Italy; gcalabrese@unime.it (G.C.); aleardizzone@unime.it (A.A.); campolom@unime.it (M.C.); sabrina.conoci@unime.it (S.C.); ipaterniti@unime.it (I.P.)

* Correspondence: eesposito@unime.it; Tel.: +39-090-6765208

+ These authors contributed equally to this work.

Abstract: Osteoarthritis (OA) is one of the most common and widespread diseases which is highly disabling for humans. This makes OA a chronic disease for which it is urgent to find new therapeutic strategies. The inflammatory state in OA contributes to its progression through multiple mechanisms involving the recruitment of phagocytes and leukocytes, inflammatory response, and reactive oxygen species (ROS) production. Tempol (4-hydroxy-2,2,6,6-tetramethylpiperidine-1-oxyl) is classifiable as a piperidine nitroxide, with excellent antioxidant effects, while its anti-inflammatory role is not yet clear. On this basis, we explored its promising biological properties in two in vitro model:, macrophage (J774) and chondrocyte (CC) cell lines. With this aim in mind, we induced inflammation in J774 and CC using lipopolysaccharide (LPS) and Interleukin1 $\beta$ (IL-1 $\beta$ ), and after 24, 72 and $168 \mathrm{~h}$ of tempol treatment analyzed their effects on cytotoxicity and anti-inflammatory activity. Our data suggested that tempol treatment is able to reduce inflammation and nitrite production in LPS-induced J774 as well as reducing the production of proinflammatory mediators including cytokines, enzymes, and metalloproteases (MMPs) in IL- $1 \beta$-stimulated CC. Thus, since inflammation and oxidative stress have a crucial role in the pathogenesis and progression of $\mathrm{OA}$, tempol could be considered as a new therapeutic approach for this pathology.

Keywords: osteoarthritis; inflammation; cartilage degeneration; synthetic molecules; tempol

\section{Introduction}

Osteoarthritis (OA) is a widespread chronic disease that causes damage to the cartilage and surrounding tissues [1] and can affect one or more anatomical districts, mainly the knee and hip as well as the spine, ankle, shoulder, and fingers. In 2019, 303 million people were affected by OA [2].

OA can be classified as primary or secondary [3]. Primary or idiopathic OA forms occur in previously intact joints without any inciting agent. Aging plays an integral part in this form of OA, as the wear and tear on the joints causes damage to the cartilage, leading to an abnormal repair mechanism. Moreover, water content increases in the superficial and middle zones, resulting from the loss of collagen integrity [4].

The secondary form of OA is caused by an underlying predisposing factor; among these, obesity and joint injury are two of the strongest modifiable risk factors [3]. In particular, rheumatoid arthritis and other inflammatory conditions of the joints lead to joint damage and cartilage breakdown.

OA develops via a combination of biochemical, cellular, and mechanical processes. It is thought to start from the breakdown, by proteolysis, of the cartilage matrix. The weak matrix is prone to fibrillation and erosion, and results in the release of proteoglycans and 
collagen fragments into the synovial fluid. This process induces an inflammatory response in the synovium, which causes further cartilage degradation. As the cartilage becomes weak it begins to thin out, causing the joint space to narrow

Although the disease has been well studied, its etiology is not fully known. A multifactorial etiopathogenesis is supposed, which could include a genetic, traumatic, or mechanical components [5]. Currently, there is no definitive treatment for the pathology; the current OA drugs are mainly used to relieve the symptoms like severe pain and inflammation, while "nonpharmacological" forms of therapy such as physiotherapy, thermotherapy, and electrostimulation are becoming commonplace [6-8]. Therefore, given the chronicity of the disease and the lack of a definitive cure, it is certainly useful to analyze and test new drugs that could be useful both in the management of musculoskeletal pain and in counteracting inflammation due to joint degeneration. Many articles have shown how the modulation of the inflammatory pathways could be an effective strategy for the treatment of OA [9], thus highlighting the role of conventional inflammatory factors in the progression of $\mathrm{OA}$.

Moreover, the overproduction of ROS and the induction of oxidative stress in chondrocytes are some of the major contributors to OA pathogenesis [10-13]. Many studies have shown that the ROS levels are highly upregulated in the human OA cartilage and CC $[12,14-16]$. It has been shown, in an in vitro study, that stimulation of human OA CC and mouse CC with IL-1 $\beta$ increases the production of the cellular and mitochondrial ROS that promotes inflammation and apoptosis $[17,18]$ showing that oxidative stress positively correlates with collagen degradation [12] suggesting a role of ROS in cartilage matrix catabolism. Thus, since oxidative stress and inflammation have detrimental effect on joint health and function, targeting these pathways might be of therapeutic importance for the management of OA. In recent years, the effects of tempol, a synthetic molecule with powerful biological properties, have been investigated and deepened [19-21].

Specifically, tempol (4-hydroxy-2,2,6,6-tetramethylpiperidine-1-oxyl) is classifiable as a piperidine nitroxide having excellent antioxidant effects with nontoxic activity [22]. This antioxidant function is related to the ability of nitroxide radicals to scavenge free radicals and oxidize transition metals in the reduced state, as well as catalyzing the disproportionation of superoxide, facilitating hydrogen peroxide metabolism, and inhibiting Fenton chemistry [23]. Furthermore, this class of compounds has been recognized as having superoxide dismutase (SOD)-like activity, given their ability to decrease superoxide ion levels and modulate nitric oxide (NO) levels [24,25]. In addition to all these properties, tempol also has the ability to penetrate the cell membrane [26] (unlike other antioxidant species that have no intracellular activity) and therefore to increase the antioxidant power. Hence, on this basis, the purpose of our study was to evaluate the anti-inflammatory and antiosteoarthritic tempol properties in both an inflammatory and an OA model in vitro.

\section{Materials and Methods}

\subsection{Cell Cultures}

In this study we used two cell lines, murine macrophage cell line (J774) and human chondrocyte cell line (CC) (C20A4 -Sigma-Aldrich, Milan, Italy). J774 cells were maintained in RPMI-1640 culture medium supplemented with $2 \mathrm{mM}$ L-Glutamine, antibioticantimycotic solution (Pen/Strep/Amphotericin, Sigma-Aldrich Company Ltd, Milan, Italy), $10 \%$ fetal bovine serum (FBS), at $37^{\circ} \mathrm{C}$ and $5 \% \mathrm{CO}_{2}$ in a humidified atmosphere. The cells were maintained in culture until $80 \%$ confluence and the medium replaced twice a week. CC were grown in complete CC culture medium and maintained in humidified environment at $37{ }^{\circ} \mathrm{C}$ and $5 \% \mathrm{CO}_{2} / 95 \%$ air atmosphere. The medium was replaced twice a week and cells were cultured until confluence was reached.

\subsection{Cytotoxicity Assay}

The cytotoxicity of tempol on J774 and CC was determined using MTT [3-(4,5dimethylthiazol-2-yl)-2,5-diphenyltetrazolium bromide] colorimetric assay as reported 
previously [27]. Briefly, J774 $\left(5 \times 10^{3}\right.$ cells/well $)$ were cultured in 96 wells and after $24 \mathrm{~h}$ fresh medium containing several concentrations of tempol $(0.1,0.2,0.5,1 \mathrm{mM}$ dissolved in $1 \%$ of DMSO) were added and incubated with LPS $(1 \mu \mathrm{g} / \mathrm{mL}$, of Escherichia coli serotype, 055:B5; Sigma-Aldrich, Milan, Italy). After $24 \mathrm{~h}$ the cells were washed and $200 \mu \mathrm{L}$ of MTT solution ( $1 \mathrm{mg} / \mathrm{mL}$ in FBS-free medium) was added to each well and incubated for $2 \mathrm{~h}$. Following $2 \mathrm{~h}$ incubation, the medium was removed, each well washed 2 times using cold phosphate-buffered saline (PBS), and the formed crystals melted using $200 \mu \mathrm{L}$ of DMSO. The optical density of the formazan product in solution was then measured with a microplate reader at $570 \mathrm{~nm}$. In another set of experiments CC $\left(5 \times 10^{3}\right.$ cells/well $)$ were cultured in 96 wells and after $24 \mathrm{~h}$ fresh medium containing tempol at two different concentrations $(0.5 \mathrm{mM}, 1 \mathrm{mM})$ was added and incubated with IL-1 $\beta(10 \mathrm{ng} / \mathrm{mL})$. After $24 \mathrm{~h}$ the cells were washed and $200 \mu \mathrm{L}$ of MTT solution was added to each well and the MTT assay was carried out as previously described.

\subsection{Griess Nitrite Assay}

For Griess nitrite $\left(\mathrm{NO}_{2}^{-}\right)$assay, J774 cells were cultured in medium containing tempol $(0.1,0.2,0.5,1 \mathrm{mM})$ for 24,72 and $168 \mathrm{~h}$, washed with fresh medium and treated with $1 \mu \mathrm{g} / \mathrm{mL}$ of LPS. After $24 \mathrm{~h}, 100 \mu \mathrm{l}$ of the culture medium was mixed with an equal volume of Griess reagent and incubated at room temperature for $10 \mathrm{~min}$ according to the manufacturer's instructions. The absorbance at $540 \mathrm{~nm}$ was recorded using a microplate reader [28].

\subsection{MMP1 and MMP3 Activity Evaluation}

For MMPs activity evaluation, supernatants from CC treated with tempol and stimulated with IL-1 $\beta(10 \mathrm{ng} / \mathrm{mL})$ after $24 \mathrm{~h}$ were collected and the levels of MMP1 and MMP3 measured by ELISA (Invitrogen, ThermoFisher Scientific, Waltham, MA, USA) according to the manufacturer's instructions.

\subsection{ROS Assay}

To measure intracellular reactive oxygen species, we used the Cellular ROS/Superoxide detection assay kit (Abcam, ab139476, Cambridge, MA, USA) [29]. CC cells plated in a black 96 -well plate (20,000 cells per well) were incubated with ROS/Superoxide detection $\operatorname{mix}(2 \mu \mathrm{M})$ for $30 \mathrm{~min}$ at $37^{\circ} \mathrm{C}$ in darkness. As positive and negative controls, the ROS inducer pyocyanin $(200 \mu \mathrm{M})$ and ROS inhibitor N-acetyl-L-cysteine $(5 \mathrm{mM})$ were used $1 \mathrm{~h}$ or $30 \mathrm{~min}$ in advance, respectively. Cells were then washed twice with washing buffer and immediately observed for fluorescein and rhodamine in a Molecular Devices Spectramax i3x. Cellular protein content was determined with a BCA-protein kit from Pierce (Thermo Fisher Scientific, Waltham, MA, USA), and the data are presented as ROS normalized to protein.

\subsection{Determination of Malondialdehyde (MDA) Levels}

CC cells $\left(1 \times 10^{5}\right.$ cells/well $)$ were seeded in poly-L-lysine-coated six-well plates. The cells were harvested to detect the levels of malondialdehyde (MDA) using the MDA assay kit as previously described [30].

\subsection{Quantitative Realtime PCR ( $q R T-P C R$ )}

For qRT-PCR analyses total RNA from CC, treated with tempol and stimulated with IL-1 $\beta(10 \mathrm{ng} / \mathrm{mL}$ ), was isolated using RNeasy Mini Isolation Kit (Qiagen, Germantown, MD, USA) and quantified as previously described [31]. cDNA was synthesized from $1 \mu \mathrm{g}$ of total RNA using M-MLV Reverse Transcriptase (Life Technologies, Monza, Italy). qRT-PCR was performed using SYBR Green method on a 7900HT Real Time PCR (Applied Biosystems). qRT-PCR analyses were performed on three independent experiments, each sample was tested in triplicate and gene expression was measured using the 2- $\Delta \Delta \mathrm{Ct}$ method. RNA from control cells was used as reference for relative expression quantitation. 
The following specific primers: COX2, IL-1 $\beta$, IL-6, iNOS, TNF- $\alpha$, and MMPs $(1,3,9,13)$ were used and designed using primer blast. Results were normalized to the levels of glyceraldehyde 3-phosphate dehydrogenase (GAPDH). Oligonucleotide sequences are reported in the Table 1.

Table 1. qRT-PCR oligonucleotide sequences.

\begin{tabular}{ccc}
\hline Homo Sapiens Gene & Forward & Reverse \\
\hline COX2 & TGCAGTGAGCGTCAGGAG & CAAGGATTTGCTGTATGGCT \\
IL-1ß & GAAGTACCTGAGCTCGCCATGGAA & CGTGCAGTTCAGTGATCGTACAGG \\
IL-6 & CAAATTCGGTACATCCTC & CTGGCTTGTTCCTCACTA \\
iNOS & TCACCTACCACACCCGAGA & CGCTGGCATTCCGCACAA \\
TNF- $\alpha$ & CAAGCCTGTAGCCCATGTTGT & CCAAAGTAGACCTGCCCAGAC \\
MMP1 & CGACTCTAGAAACACAAGAGCAAGA & AAGGTTAGCTTACTGTCACACGCTT \\
MMP3 & GAACAATGGACAAAGGATACAACA & TTCTTCAAAAACAGCATCAATCTT \\
MMP13 & CACTGTCCACCCCTCAGAGC & GCCACTTGTCGGCGATAAGG \\
GAPDH & GTGGTGTGGGAAGTATCATCA & GCATCTGGAGTAACCGTATTG \\
& GGAGAAGGCTGGGGCTCAT & TGGGTGGCAGTGATGGCA \\
\hline
\end{tabular}

\subsection{Materials}

J774 and CC (C20A4 -human chondrocyte cell line) were purchased from Sigma Aldrich, as well as tempol, MTT, LPS, antibiotic-antimycotic solution (Pen/Strep/Amphotericin, SigmaAldrich Company Ltd, Milan, Italy) and FBS. L-Glutamine was purchased from Euroclone. All stock solutions were made in nonpyrogenic saline $(0.9 \% \mathrm{NaCl}$, Baxter, Milan, Italy). All other chemicals were of the highest commercial grade available.

\subsection{Statistical Analysis}

Statistical analysis was performed by one-way ANOVA followed by Bonferroni multiple comparisons test where appropriate. Bonferroni method has been used as post hoc test when the ANOVA reported statistically significant differences, to evaluate the differences between the individual times or treatment groups. For all experiments, $p<0.05$ was considered to be significant.

\section{Results}

\subsection{Effects of Tempol on Macrophages Cell Viability}

To evaluate the cytotoxic effect of different concentrations $(0.1,0.2,0.5,1 \mathrm{mM})$ of tempol on both J774 and LPS-induced J774 cells, we performed a MTT colorimetric test. The data reported in Figure 1A show that tempol does not exhibit significant cytotoxic effects on J774 cells at all lower concentrations used $(0.1-0.2 \mathrm{mM})$ at all timepoints of treatment, while after $168 \mathrm{~h}$ of incubation it is possible to notice a slight trend of reduction in cell viability, especially at the higher concentration (Figure 1A) and especially at 72 and $168 \mathrm{~h}$. Instead, J774 cells induced with LPS displayed a significantly reduction in cell viability as shown in Figure 1B, whereas treatment with tempol only showed a recovery of cell viability at the highest concentrations of 0.5 and $1 \mathrm{mM}$ compared to treatment with LPS alone (Figure 1B).

\subsection{Effects of Tempol on LPS-Induced NO Production in J774 Cells}

In order to evaluate the anti-inflammatory property of tempol, NO levels of J774 cells stimulated with LPS and treated with the selected concentrations $(0.1-1.0 \mathrm{mM})$ for 24 , 72 and 168 h were measured; our results showed slight cytotoxicity, especially at high concentrations of tempol. Our data showed that NO produced by LPS-stimulated J774 cells was significantly inhibited only at the two highest concentrations in time dependent manner (Figure 1C), even if the $1.0 \mathrm{mM}$ concentration was more effective. Since only the two highest concentrations ( 0.5 and $1.0 \mathrm{mM}$ ) of tempol were able to significantly increase 
cell viability as well as reduced NO levels in LPS-stimulated J774, we decided to perform all further experiments with only these two concentrations.

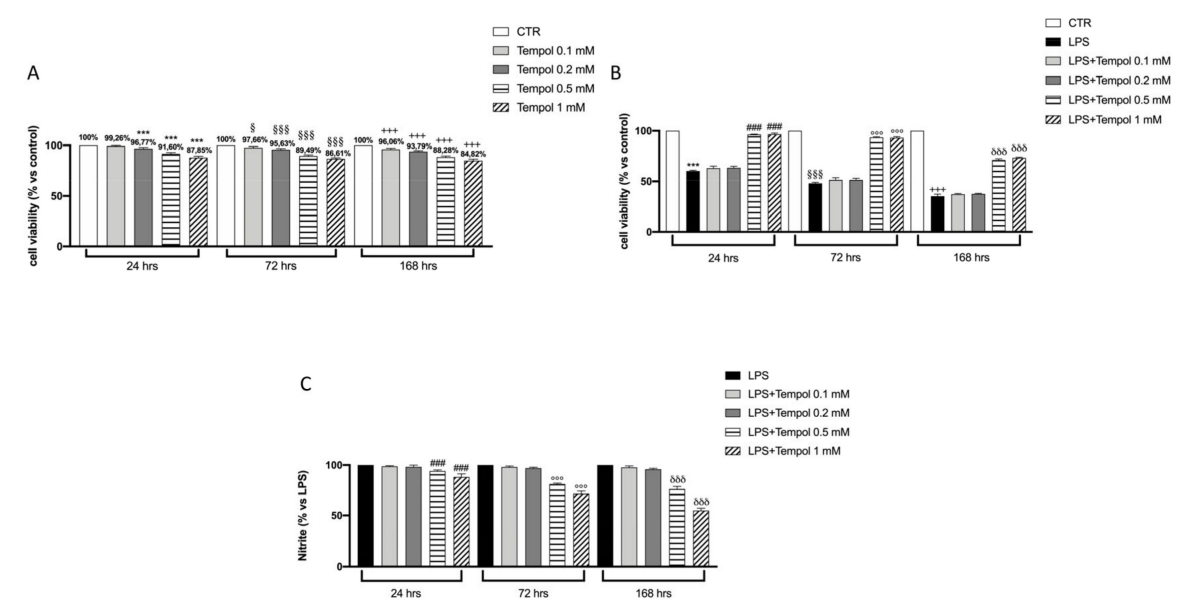

Figure 1. Effects of tempol on J774 cell viability and nitric oxide production. MTT test performed on J774, without and with LPS stimulation, treated with tempol $(0.1,0.2,0.5$ and $1 \mathrm{mM})$ for 24 , 72 and $168 \mathrm{~h}(\mathbf{A}, \mathbf{B})$. Griess assay performed on the supernatant of LPS-stimulated J774 treated with different concentrations of tempol for 24, 72 and $168 \mathrm{~h}$ (C). Control (CTR), untreated J774 cells, LPS, J774 stimulated with LPS. Data are represented as the means \pm SD of three independent experiments. One-way ANOVA test. $\S$ compare the LPS group $72 \mathrm{~h}$ to CTR group; ${ }^{* * *} p<0.001$ vs. CTR $24 \mathrm{~h}$; $\S \S \S p<0.001$ vs. CTR $72 \mathrm{~h} ;{ }^{+++} p<0.001$ vs. CTR $168 \mathrm{~h} ;{ }^{\# \#} p<0.001$ vs. LPS $24 \mathrm{~h} ;{ }^{\circ 00} p<0.001$ vs. LPS $72 \mathrm{~h} ;{ }^{\delta \delta \delta} p<0.001$ vs. LPS $168 \mathrm{~h}$.

\subsection{Effects of te3mpol on CC Cell Viability}

Before carrying out further in vitro tests on CC cells, it was necessary to evaluate the cytotoxic effects of tempol at the two selected concentrations $(0.5$ and $1.0 \mathrm{mM})$ on CC alone and CC stimulated with IL-1 $\beta$ at $10 \mathrm{ng} / \mathrm{mL}$. The effects of tempol on cell viability are shown in Figure 2A. Our results showed that tempol, at both concentrations, slightly reduces cell viability at all times analyzed (Figure $2 \mathrm{~A}$ ), and IL-1 $\beta$ at $10 \mathrm{ng} / \mathrm{mL}$ induces a significant reduction of cell viability at all timepoints (Figure 2B).

We observed that tempol, at both concentrations, displayed a recovery of cell viability compared to treatment with IL-1 $\beta$ alone (Figure 2B).

\subsection{Effects of Tempol on IL-1 $\beta$-Induced Inflammatory me3diators and MMPs}

To evaluate the protective effects of tempol on IL-1 $\beta$-stimulated CC we performed qRTPCR to analyze the gene expression of inflammatory mediators (Figures 3 and 4) and MMPs (Figure 5) after 24, 72 and $168 \mathrm{~h}$ of treatment. Our data indicate that after $24 \mathrm{~h}$ of treatment with tempol at $0.5 \mathrm{mM}$ no significant effect was noticeable in IL-1 $\beta$ (Figure 3B), COX-2 and iNOS (Figure 4A,B respectively) as well as in MMP13 (Figure 5D) expression levels; while a significant reduction was visible for TNF- $\alpha$ and IL-6 (Figure 3A,C respectively) and for MMP1 and MMP13 (Figure 5A-C, respectively) compared to the IL-1 $\beta$ stimulated CC. On the other hand, treatment with tempol $1.0 \mathrm{mM}$ was able to reduce the levels of all analyzed genes in a statistically significant manner, at all timepoints analyzed, compared to the IL-1 $\beta$ group. In order to assess the effects of tempol on IL-1 $\beta$-stimulated MMP1 and MMP3 production we performed two ELISA assays. The results showed that MMP1 and MMP3 production in IL-1 $\beta$-stimulated CC increased significantly (MMP1, $462.74 \pm 62.71 \mathrm{pg} / \mathrm{mL} ; \mathrm{MMP} 3,73.11 \pm 8.81 \mathrm{ng} / \mathrm{mL}$ ) compared to the control (MMP1, $76.36 \pm 19.89 \mathrm{pg} / \mathrm{mL} ; \mathrm{MMP} 3,14.88 \pm 1.81 \mathrm{ng} / \mathrm{mL}$ ) and that the MMP1 and MMP3 activities of IL-1 $\beta$-induced CC were significantly reduced by tempol at both concentrations (Figure 5E,F respectively) (MMP1: tempol $0.5 \mathrm{mM} \_272.49 \pm 43.83 \mathrm{pg} / \mathrm{mL}$ and tempol $1.0 \mathrm{mM} \_139.85 \pm 21.80 \mathrm{pg} / \mathrm{mL}$; MMP3: tempol $0.5 \mathrm{mM} \_53.83 \pm 3.95 \mathrm{ng} / \mathrm{mL}$, tempol $1.0 \mathrm{mM} \_33.13 \pm 6.81 \mathrm{ng} / \mathrm{mL}$ ) (Figure 5E,F, respectively). To confirm the anti-inflammatory 
effect of tempol we also evaluated the levels of proinflammatory cytokines such as TNF- $\alpha$ and IL-1 $\beta$ by Elisa kit assay (see Supplementary Materials Figure S1), as well as which we observed the protein expression of COX-2 and iNOS by Western blot (see Supplementary Materials Figures S2 and S3, respectively). The data obtained confirmed the capacity of tempol to reduce, both at 72 and $168 \mathrm{~h}$, the inflammatory markers.

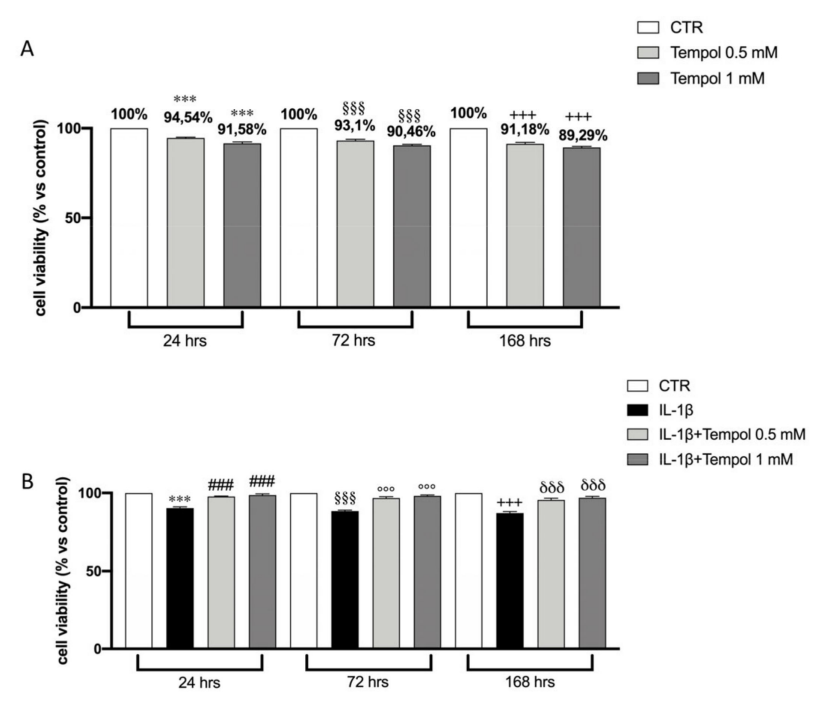

Figure 2. Effects of tempol on CC cell viability. MTT test performed on CC treated with tempol $(0.5$ and $1 \mathrm{mM})$ for 24,72 and $168 \mathrm{~h}(\mathrm{~A})$. MTT test performed on IL-1 $\beta$-stimulated CC and treated with tempol (0.5 mM and $1.0 \mathrm{mM}$ ) for 24, 72 and $168 \mathrm{~h}(\mathbf{B})$. CTR, untreated CC; IL-1 $\beta$, Il-1 $\beta$ stimulated $\mathrm{CC}$; Data are represented as the means $\pm \mathrm{SD}$ of three independent experiments. One-way ANOVA

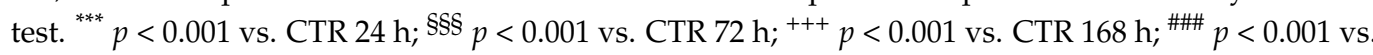
IL-1 $\beta 24 \mathrm{~h} ;{ }^{\circ 00} p<0.001$ vs. IL-1 $\beta 72 \mathrm{~h} ;{ }^{\delta \delta \delta} p<0.001$ vs. IL-1 $\beta 168 \mathrm{~h}$.

A
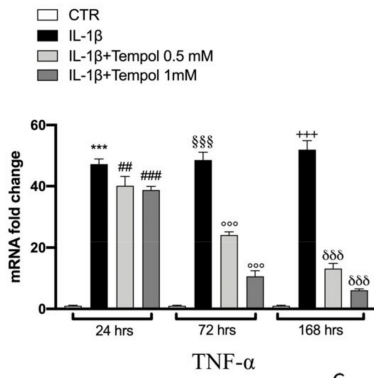

C $\square \mathrm{IL}-1 \beta$

IL-1 $1 \beta+$ Tempol $0.5 \mathrm{mM}$

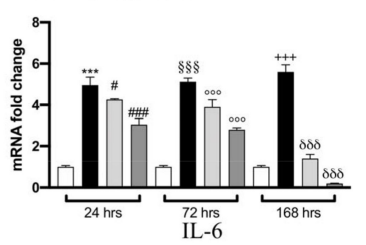

B $\square$ CTR

$\square$ IL-1 $1 \beta+$ Tempol $0.5 \mathrm{mM}$

IL-1 $\beta+$ Tempol $1 \mathrm{mM}$

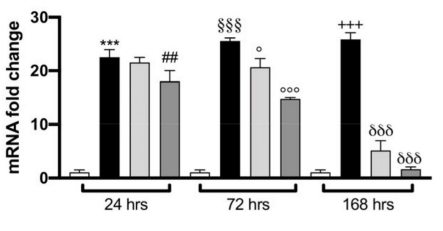

IL-1 $\beta$

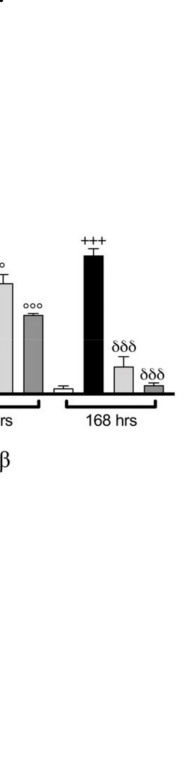

Figure 3. Effects of tempol on IL-1 $\beta$-induced inflammatory cytokines gene expression. qRT-PCR performed with IL-1 $\beta$ (B), IL-6 (C) and TNF- $\alpha$ (A) on IL-1 $\beta$-stimulated CC and treated with tempol $(0.5$ and $1.0 \mathrm{mM}$ ) for 24,72 and $168 \mathrm{~h}$. GAPDH was used as endogenous controls. CTR, untreated CC; IL-1 $\beta$, IL-1 $\beta$-stimulated CC; IL-1 $\beta$ +tempol, IL-1 $\beta$-stimulated CC and treated with tempol 0.5 and 1.0 mM. Data are representative of at least three independent experiments. One-way ANOVA test. compare the LPS-tempol group $72 \mathrm{~h}$ to IL1 beta group; ${ }^{* * *} p<0.001 \mathrm{vs}$. CTR $24 \mathrm{~h}$; $\$ \$ \$ p<0.001 \mathrm{vs}$. CTR $72 \mathrm{~h} ;{ }^{+++} p<0.001$ vs. CTR $168 \mathrm{~h}$; ${ }^{* \# \#} p<0.001$ vs. LPS $24 \mathrm{~h} ;{ }^{\# \#} p<0.01$ vs. LPS $24 \mathrm{~h}$; ${ }^{\#} p<0.05$ vs. LPS $24 \mathrm{~h} ;{ }^{\circ 00} p<0.001$ vs. LPS $72 \mathrm{~h} ;{ }^{\delta 8 \delta} p<0.001$ vs. LPS $168 \mathrm{~h}$. 


$$
\text { A }
$$
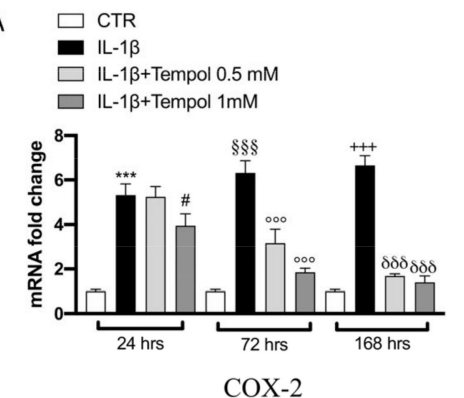

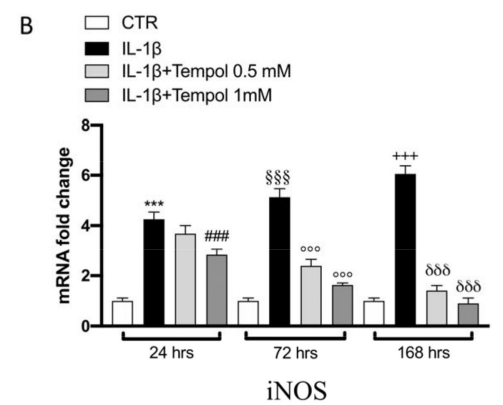

Figure 4. Effects of tempol on IL-1 $\beta$-induced inflammatory enzymes gene expression. qRT-PCR performed with COX-2 (A) and i-NOS (B) on IL-1 $\beta$-stimulated CC and treated with tempol (0.5 and 1.0 $\mathrm{mM}$ ) for 24, 72 and $168 \mathrm{~h}$. GAPDH was used as endogenous controls. CTR, untreated CC; IL-1 $\beta$, IL-1 $\beta$-stimulated CC; IL-1 $\beta$ +tempol, IL- $1 \beta$-stimulated CC and treated with tempol 0.5 and $1.0 \mathrm{mM}$. Data are representative of at least three independent experiments. One-way ANOVA test. ${ }^{* * *} p<0.001$ vs. CTR $24 \mathrm{~h}$; $\$ \S \S p<0.001$ vs. CTR $72 \mathrm{~h} ;{ }^{+++} p<0.001$ vs. CTR $168 \mathrm{~h}$; \#\#\# $p<0.001$ vs. LPS 24 h; \# $p<0.05$ vs. LPS $24 \mathrm{~h} ;{ }^{\circ 00} p<0.001$ vs. LPS $72 \mathrm{~h} ; \delta \delta \delta p<0.001$ vs. LPS $168 \mathrm{~h}$.
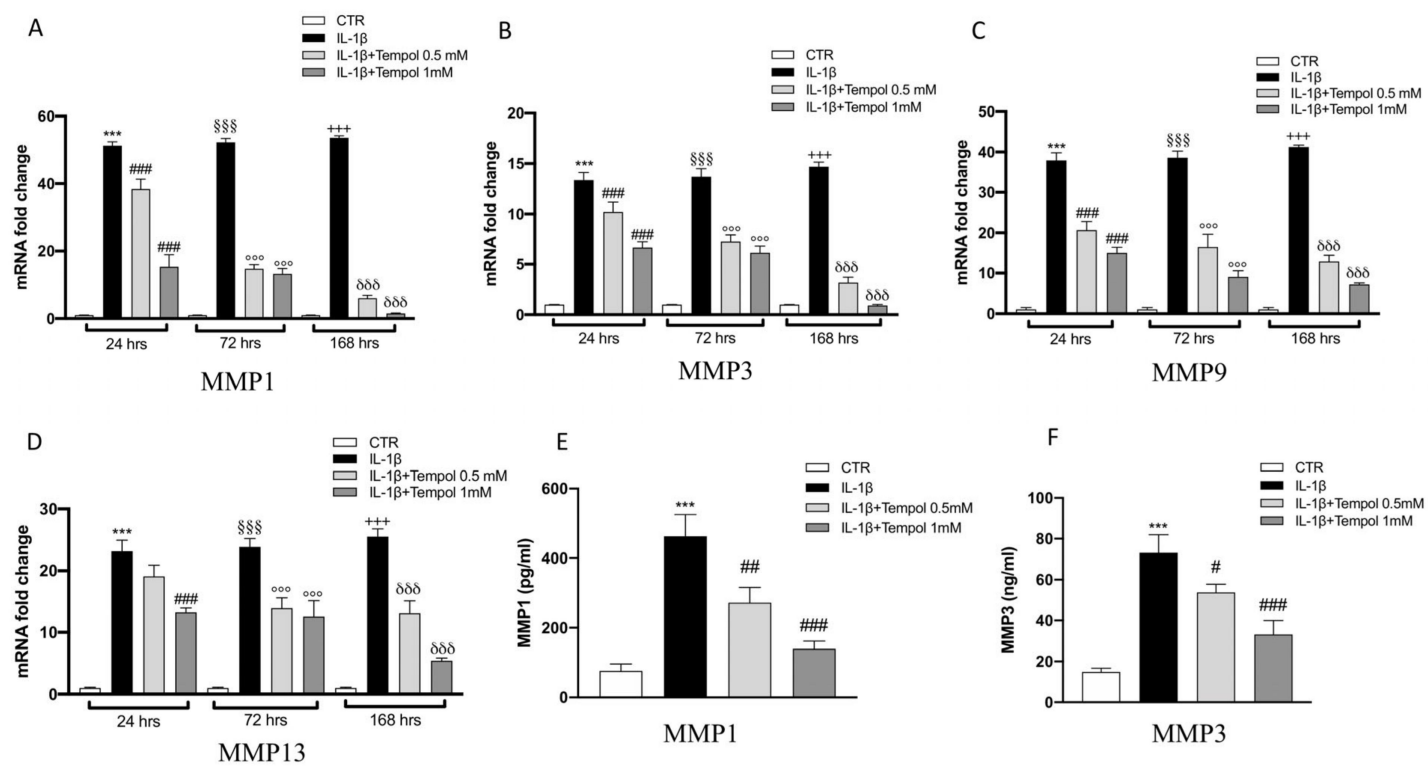

Figure 5. Effects of tempol on IL-1 $\beta$-induced MMPs activity and gene expression. IL-1 $\beta$-stimulated CC were treated with 0.5 and $1.0 \mathrm{mM}$ of tempol for 24, 72 and $168 \mathrm{~h}$. Expression of MMP1 (A), MMP3 (B), MMP9 (C) and MMP13 (D) was evaluated using real time-PCR. CTR, control untreated CC; IL- $1 \beta$, IL- $1 \beta$-stimulated CC; IL- $1 \beta$ +tempol, IL- $1 \beta$-stimulated CC and treated with tempol 0.5 and $1.0 \mathrm{mM}$. GAPDH was used as endogenous controls. Moreover, MMP activity was evaluated by ELISA kit assay (E,F). Data are representative of at least three independent experiments. One-way ANOVA test. ${ }^{* * *} p<0.001$ vs. CTR $24 \mathrm{~h}$; $\$ \& \S p<0.001$ vs. CTR $72 \mathrm{~h} ;{ }^{+++} p<0.001$ vs. CTR $168 \mathrm{~h} ;{ }^{\# \#} p<0.001$ vs. LPS $24 \mathrm{~h} ;{ }^{\# \#} p<0.01$ vs. LPS $24 \mathrm{~h}$; ${ }^{\#} p<0.05$ vs. LPS $24 \mathrm{~h} ;{ }^{\circ 00} p<0.001$ vs. LPS $72 \mathrm{~h} ;{ }^{\delta \delta \delta} p<0.001$ vs. LPS $168 \mathrm{~h}$.

\subsection{Antioxidant Effects of Tempol on Oxidative Stress}

Another important issue in OA pathogenesis is the production of ROS and induction of oxidative stress in CC. Thus, we evaluated the antioxidant effect of tempol in reducing ROS production by ROS assay. We observed that there was a significant increase of ROS production after IL- $1 \beta$-stimulation compared to CC control group at each timepoint (Figure 6A); whereas the treatment of tempol significantly decreased ROS production in a concentration dependent manner at each timepoint (Figure 6A).

ROS production correlates to and determinates the lipidic peroxidation of the membranes that was evaluated by MDA assay. We observed an important increase in the 
levels of MDA after IL-1 $\beta$-stimulation compared to CC control group at each timepoints (Figure 6B); treatment with tempol was able to significantly reduce MDA levels in a concentration-dependent manner at each timepoints (Figure 6B).

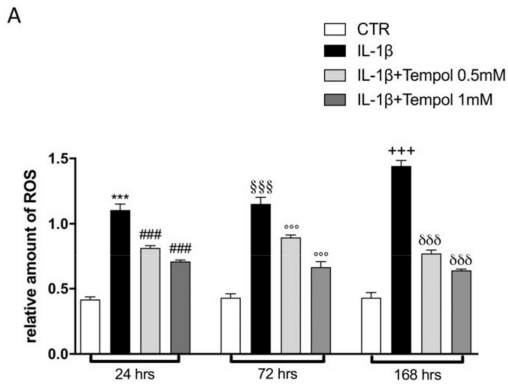

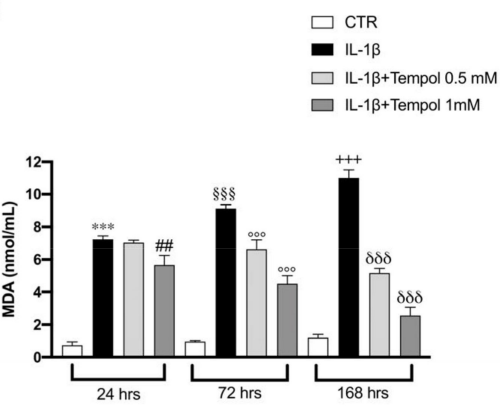

Figure 6. Effects of tempol on oxidative stress. Evaluation of oxidative stress was assessed by ROS assay and MDA assay. CTR, control untreated CC; IL- $1 \beta$, IL-1 $\beta$-stimulated CC; IL- $1 \beta+$ tempol, IL-1 $\beta$-stimulated CC and treated with tempol 0.5 and $1.0 \mathrm{mM}$. Treatments with tempol 0.5 and $1.0 \mathrm{mM}$ notably reduced intracellular ROS concentrations increment IL-1 $\beta$-induced (A) as well as prevented the elevated lipidic peroxidation caused by IL-1 $\beta$-stimulation (B). Data are representative of at least three independent experiments. One-way ANOVA test. ${ }^{* * *} p<0.001$ vs. CTR $24 \mathrm{~h}$; $\S \S \S p<0.001$ vs. CTR $72 \mathrm{~h} ;{ }^{+++} p<0.001$ vs. CTR $168 \mathrm{~h} ;{ }^{\# \# \#} p<0.001$ vs. LPS $24 \mathrm{~h} ;{ }^{\# \#} p<0.01$ vs. LPS $24 \mathrm{~h} ;{ }^{\circ 00} p<0.001$ vs. LPS $72 \mathrm{~h} ;{ }^{\delta \delta \delta} p<0.001$ vs. LPS $168 \mathrm{~h}$.

\section{Discussion}

Osteoarthritis $(\mathrm{OA})$ is one of the most disabling joint disorders worldwide, still lacking a resolutive therapeutic strategy [2]. Despite the fact that OA is correlated to genetic predisposition and epigenetic regulation [32], it is possible to act by attenuating the inflammatory condition that underlies the pathology [33,34]. The inflammatory state in OA, and in particular the increase in the expression of some inflammatory mediators, contributes to the progression of the disease through multiple mechanisms that involve the recruitment of phagocytes and leukocytes [35,36], intrinsic inflammatory response [35,37] and ROS production [38]. Therefore, the control of the inflammatory condition could represent one of the strategies for better management of the symptoms and the advancement of OA. Multiple studies have evaluated the excellent antioxidant activity of tempol to counteract oxidative stress conditions $[39,40]$ due to the presence of a nitroxide ion, which gives it the ability to be a "radical scavenger"; while its anti-inflammatory role is still under continuous investigation [41]. Based on this knowledge, the aim of this study was to investigate, for the first time, the capacity of tempol to reduce the inflammatory stimuli associated with OA pathogenesis. In particular, for the in vitro model of OA, a CC line was used in order to have a model that is as appropriate as possible and that attempts to mimic the factors and conditions that trigger $\mathrm{OA}$ and cause its progression [42], as well as being reliable for verifying new therapeutic potentials. Cell viability tests performed by MTT assay on both J774 and CC cell lines reveal a slight cytotoxicity of tempol, especially at the high concentrations used, compared to the control. As observed from our results, when CC were stimulated with IL-1 $\beta$ they showed a slight reduction in cell viability instead treatment of tempol, especially at 0.5 and $1.0 \mathrm{mM}$, demonstrated a recovery in cell viability time-dependent manner. Since the presence of macrophages concentrated in the synovial tissue contribute to the promotion of the inflammatory microenvironment and contribute to the onset and progression of OA by interacting with CC and fibroblasts $[43,44]$, in this study we investigated the anti-inflammatory activity of tempol using a macrophage cell line. Specifically, we stimulated J774 cells with LPS for $24 \mathrm{~h}$ and observed that the induction of the inflammatory state determinates a reduction in cell viability in a time-dependent manner; instead the treatment with tempol, especially at 0.5 and $1 \mathrm{mM}$, was able to recover cell viability, as the control, showing a protective activity. Inflammation is a major factor associated with the risk of both progression of cartilage loss and signs and symptoms 
of OA, including joint pain, swelling, and stiffness, indicators of synovitis [45]. Synovitis, involving the infiltration of mononuclear cells into the synovial membrane and the production of proinflammatory mediators, including IL- $1 \beta$, TNF- $\alpha$ and chemokines, is common in early stage and late stage disease [42]. Therefore, considering the relevant role of these mediators in the initiation of the inflammatory cascade in OA, in this study we evaluated their expressions by qRT-PCR. Our results showed that tempol, at concentrations of 0.5 and $1 \mathrm{mM}$, was able to decrease the expression of cytokines, especially of TNF- $\alpha$. IL-1 $\beta$ and TNF- $\alpha$ increase the synthesis of prostaglandin E2 (PGE2) by stimulating COX-2 gene expression and upregulating the production of $\mathrm{NO}$ via inducible nitric oxide synthase iNOS $[45,46]$. Here we observed that at $0.5 \mathrm{mM}$, but even more at $1.0 \mathrm{mM}$, tempol has shown promise effects in decreasing iNOS and COX-2 expressions. Several clinical studies $[47,48]$ have pointed out that in patients with OA there are elevated levels of MMPs; the action of these proteases contributes enormously to cartilage degradation, increasing joint damage, thus accelerating the progression of joint destruction [49]. Since MMPs play an important role in the pathogenesis of $\mathrm{OA}$, an extensive analysis of these proteases and specifically of MMP1, MMP3, MMP9 and MMP13 was performed; treatment with tempol at $1.0 \mathrm{mM}$ considerably reduced their expression, as is clearly demonstrated by our results. Although in the last decade much knowledge about inflammatory mediators in OA has been gained, further studies are needed to better define the mechanisms by which these factors tip the balance between homeostasis and activation to promote matrix destruction and cell death. In line with this idea, our study demonstrates for the first time the important anti-inflammatory properties of tempol in counteracting the response of CC to the inflammatory insults that characterized OA.

\section{Conclusions}

In conclusion, although the present work needs further validation, especially in vivo, it supports the idea that tempol treatment, at 0.5 and $1.0 \mathrm{mM}$ concentrations, can be considered as a new therapeutic approach for inflammatory states, including OA, because in addition to having a protective effect on cell viability, it is able to modulate NO production in J774 and all inflammatory mediators in CC, even after only $24 \mathrm{~h}$ of treatment.

Supplementary Materials: The following are available online at https: / www.mdpi.com/2218-2 73X/11/3/352/s1, Figure S1: Effects of tempol on IL-1 $\beta$ and TNF- $\alpha$ expression. ELISA kit was performed both 72 and $168 \mathrm{~h}$ after CC stimulation with IL-1 $\beta$. TNF- $\alpha$ and IL-1 $\beta$ levels were overexpressed on IL-1 $\beta$-stimulated CC compared to CTR group at both timepoints (A, B, C, D). Treatment with tempol $(0.5 \mathrm{mM}$ and $1.0 \mathrm{mM})$ significantly reduced levels of both cytokines after $72 \mathrm{~h}$ and 7 days $(\mathrm{A}, \mathrm{B}, \mathrm{C}, \mathrm{D})$. Data are representative of at least three independent experiments. One-way ANOVA test. ${ }^{* * *} p<0.001$ vs. CTR; \#\# $p<0.01$ vs. IL-1 $\beta$; \#\#\# $p<0.001$ vs. IL- $1 \beta$. Figure S2: Effects of tempol on COX-2 expression. Western blot analysis demonstrated an increase of COX-2 expression after IL-1 $\beta$ stimulation, both at 72 and $168 \mathrm{~h}$, compared to CTR group (A,A1 and B,B1 respectively). Tempol $(0.5 \mathrm{mM}$ and $1.0 \mathrm{mM})$ significantly decreased these levels at both timepoints (A,A1 and $\mathrm{B}, \mathrm{B} 1)$. Data are representative of at least three independent experiments. One-way ANOVA test. *** $p<0.001$ vs. CTR; \#\# $p<0.01$ vs. IL-1 $\beta$; \#\#\# $p<0.001$ vs. IL-1 $\beta$. Figure S3: Effects of tempol on iNOS expression. Western blot analysis of iNOS showed a significant increase in CC stimulated with IL-1 $\beta$ after 72 and $168 \mathrm{~h}$ (A,A1 and B,B1. Treatment with tempol $(0.5 \mathrm{mM}$ and $1.0 \mathrm{mM})$ considerably reduced iNOS expression already after $72 \mathrm{~h}$ and even more after $168 \mathrm{~h}(\mathrm{~A}, \mathrm{~A} 1$ and B,B1). Data are representative of at least three independent experiments. One-way ANOVA test. ${ }^{* * *} p<0.001$ vs. CTR; \#\#\# $p<0.001$ vs. IL-1 $\beta$.

Author Contributions: All authors had substantial contribution to the present work. Specifically, E.E. and I.P. conceived the project, designed the experiments and wrote the paper; A.A. and G.C. performed the experiments; G.C. and M.C. performed analysis statistical and formal analysis; S.C. supervised the project; E.E. conceived the project and revised the paper. E.E. is also the corresponding author. All authors contributed towards data analysis, drafting and critically revising the paper, gave final approval of the version to be published, and agreed to be accountable for all aspects of the work. 
Funding: This research received no external funding.

Institutional Review Board Statement: Not applicable.

Informed Consent Statement: Not applicable.

Data Availability Statement: The data presented in this study are available on request from the corresponding author.

Conflicts of Interest: The authors declare no conflict of interest.

\section{References}

1. Pereira, D.; Ramos, E.; Branco, J. Osteoarthritis. Acta Med. Port. 2015, 28, 99-106. [CrossRef]

2. Kloppenburg, M.; Berenbaum, F. Osteoarthritis year in review 2019: Epidemiology and therapy. Osteoarthr. Cartil. 2020, 28, 242-248. [CrossRef]

3. Taruc-Uy, R.L.; Lynch, S.A. Diagnosis and treatment of osteoarthritis. Prim. Care 2013, 40, 821-836. [CrossRef]

4. Mow, V.C.; Holmes, M.H.; Lai, W.M. Fluid transport and mechanical properties of articular cartilage: A review. J. Biomech. 1984, 17, 377-394. [CrossRef]

5. Glyn-Jones, S.; Palmer, A.J.; Agricola, R.; Price, A.J.; Vincent, T.L.; Weinans, H.; Carr, A.J. Osteoarthritis. Lancet 2015, 386, 376-387. [CrossRef]

6. Ferreira, R.M.; Torres, R.T.; Duarte, J.A.; Goncalves, R.S. Non-Pharmacological and Non-Surgical Interventions for Knee Osteoarthritis: A Systematic Review and Meta-Analysis. Acta Reumatol. Port. 2019, 44, 173-217. [PubMed]

7. Richter, K.; Muller-Ladner, U.; Dischereit, G.; Uwe, L. Potentials and Limits of Physiotherapy in Osteoarthritis. Curr. Rheumatol. Rev. 2018, 14, 117-122. [CrossRef]

8. Rutjes, A.W.; Nuesch, E.; Sterchi, R.; Kalichman, L.; Hendriks, E.; Osiri, M.; Brosseau, L.; Reichenbach, S.; Juni, P. Transcutaneous electrostimulation for osteoarthritis of the knee. Cochrane Database Syst. Rev. 2009. [CrossRef]

9. Shen, J.; Abu-Amer, Y.; O'Keefe, R.J.; McAlinden, A. Inflammation and epigenetic regulation in osteoarthritis. Connect. Tissue Res. 2017, 58, 49-63. [CrossRef] [PubMed]

10. Bolduc, J.A.; Collins, J.A.; Loeser, R.F. Reactive oxygen species, aging and articular cartilage homeostasis. Free Radic. Biol. Med. 2019, 132, 73-82. [CrossRef]

11. Lepetsos, P.; Papavassiliou, A.G. ROS/oxidative stress signaling in osteoarthritis. Biochim. Biophys. Acta 2016, 1862, 576-591. [CrossRef]

12. Altindag, O.; Erel, O.; Aksoy, N.; Selek, S.; Celik, H.; Karaoglanoglu, M. Increased oxidative stress and its relation with collagen metabolism in knee osteoarthritis. Rheumatol. Int. 2007, 27, 339-344. [CrossRef] [PubMed]

13. Loeser, R.F. The Role of Aging in the Development of Osteoarthritis. Trans. Am. Clin. Climatol. Assoc. 2017, 128, 44-54. [PubMed]

14. Ansari, M.Y.; Khan, N.M.; Ahmad, I.; Haqqi, T.M. Parkin clearance of dysfunctional mitochondria regulates ROS levels and increases survival of human chondrocytes. Osteoarthr. Cartil. 2018, 26, 1087-1097. [CrossRef]

15. Loeser, R.F.; Collins, J.A.; Diekman, B.O. Ageing and the pathogenesis of osteoarthritis. Nat. Rev. Rheumatol. 2016, 12, 412-420. [CrossRef]

16. Afonso, V.; Champy, R.; Mitrovic, D.; Collin, P.; Lomri, A. Reactive oxygen species and superoxide dismutases: Role in joint diseases. Jt. Bone Spine 2007, 74, 324-329. [CrossRef] [PubMed]

17. Carlo, M.D., Jr.; Loeser, R.F. Increased oxidative stress with aging reduces chondrocyte survival: Correlation with intracellular glutathione levels. Arthritis Rheum. 2003, 48, 3419-3430. [CrossRef]

18. Collins, J.A.; Wood, S.T.; Nelson, K.J.; Rowe, M.A.; Carlson, C.S.; Chubinskaya, S.; Poole, L.B.; Furdui, C.M.; Loeser, R.F. Oxidative Stress Promotes Peroxiredoxin Hyperoxidation and Attenuates Pro-survival Signaling in Aging Chondrocytes. J. Biol. Chem. 2016, 291, 6641-6654. [CrossRef]

19. Lahiani, A.; Hidmi, A.; Katzhendler, J.; Yavin, E.; Lazarovici, P. Novel Synthetic PEGylated Conjugate of alpha-Lipoic Acid and Tempol Reduces Cell Death in a Neuronal PC12 Clonal Line Subjected to Ischemia. ACS Chem. Neurosci. 2016, 7, $1452-1462$. [CrossRef] [PubMed]

20. Phungphong, S.; Kijtawornrat, A.; Wattanapermpool, J.; Bupha-Intr, T. Improvement in cardiac function of ovariectomized rats by antioxidant tempol. Free Radic. Biol. Med. 2020, 160, 239-245. [CrossRef]

21. Silva, D.A.D.; Correia, T.M.L.; Pereira, R.; da Silva, R.A.A.; Augusto, O.; Queiroz, R.F. Tempol reduces inflammation and oxidative damage in cigarette smoke-exposed mice by decreasing neutrophil infiltration and activating the Nrf2 pathway. Chem. Biol. Interact. 2020, 329, 109210. [CrossRef]

22. Wang, M.; Li, K.; Zou, Z.; Li, L.; Zhu, L.; Wang, Q.; Gao, W.; Wang, Y.; Huang, W.; Liu, R.; et al. Piperidine nitroxide Tempol enhances cisplatin-induced apoptosis in ovarian cancer cells. Oncol. Lett. 2018, 16, 4847-4854. [CrossRef]

23. Wilcox, C.S.; Pearlman, A. Chemistry and antihypertensive effects of tempol and other nitroxides. Pharmacol. Rev. 2008, 60, 418-469. [CrossRef] [PubMed]

24. Dornas, W.C.; Silva, M.; Tavares, R.; de Lima, W.G.; dos Santos, R.C.; Pedrosa, M.L.; Silva, M.E. Efficacy of the superoxide dismutase mimetic tempol in animal hypertension models: A meta-analysis. J. Hypertens. 2015, 33, 14-23. [CrossRef] [PubMed] 
25. Jia, D.; Wang, H.; Han, B.; Zhang, L.; Guo, J. Tempol Attenuates Neuropathic Pain by Inhibiting Nitric Oxide Production. Anal. Cell Pathol. 2019, 2019, 8253850. [CrossRef] [PubMed]

26. Cuzzocrea, S.; McDonald, M.C.; Mazzon, E.; Dugo, L.; Lepore, V.; Fonti, M.T.; Ciccolo, A.; Terranova, M.L.; Caputi, A.P.; Thiemermann, C. Tempol, a membrane-permeable radical scavenger, reduces dinitrobenzene sulfonic acid-induced colitis. Eur. J. Pharmacol. 2000, 406, 127-137. [CrossRef]

27. Calabrese, G.; Dolcimascolo, A.; Caruso, G.; Forte, S. miR-19a Is Involved In Progression And Malignancy Of Anaplastic Thyroid Cancer Cells. OncoTargets Ther. 2019, 12, 9571-9583. [CrossRef] [PubMed]

28. Adesso, S.; Paterniti, I.; Cuzzocrea, S.; Fujioka, M.; Autore, G.; Magnus, T.; Pinto, A.; Marzocco, S. AST-120 Reduces Neuroinflammation Induced by Indoxyl Sulfate in Glial Cells. J. Clin. Med. 2018, 7. [CrossRef] [PubMed]

29. Tiemeier, G.L.; Wang, G.; Dumas, S.J.; Sol, W.; Avramut, M.C.; Karakach, T.; Orlova, V.V.; van den Berg, C.W.; Mummery, C.L.; Carmeliet, P.; et al. Closing the Mitochondrial Permeability Transition Pore in hiPSC-Derived Endothelial Cells Induces Glycocalyx Formation and Functional Maturation. Stem Cell Rep. 2019, 13, 803-816. [CrossRef]

30. Meng, X.; Wang, M.; Sun, G.; Ye, J.; Zhou, Y.; Dong, X.; Wang, T.; Lu, S.; Sun, X. Attenuation of Abeta25-35-induced parallel autophagic and apoptotic cell death by gypenoside XVII through the estrogen receptor-dependent activation of Nrf2/ARE pathways. Toxicol. Appl. Pharmacol. 2014, 279, 63-75. [CrossRef] [PubMed]

31. Vicari, L.; Calabrese, G.; Forte, S.; Giuffrida, R.; Colarossi, C.; Parrinello, N.L.; Memeo, L. Potential Role of Activating Transcription Factor 5 during Osteogenesis. Stem Cells Int. 2016, 2016, 5282185. [CrossRef]

32. Geyer, M.; Schonfeld, C. Novel Insights into the Pathogenesis of Osteoarthritis. Curr. Rheumatol. Rev. 2018, 14, 98-107. [CrossRef] [PubMed]

33. Conaghan, P.G.; Cook, A.D.; Hamilton, J.A.; Tak, P.P. Therapeutic options for targeting inflammatory osteoarthritis pain. Nat. Rev. Rheumatol. 2019, 15, 355-363. [CrossRef] [PubMed]

34. Liu-Bryan, R.; Terkeltaub, R. Emerging regulators of the inflammatory process in osteoarthritis. Nat. Rev. Rheumatol. 2015, 11, 35-44. [CrossRef] [PubMed]

35. Scanzello, C.R. Role of low-grade inflammation in osteoarthritis. Curr. Opin. Rheumatol. 2017, 29, 79-85. [CrossRef]

36. Griffin, T.M.; Scanzello, C.R. Innate inflammation and synovial macrophages in osteoarthritis pathophysiology. Clin. Exp. Rheumatol. 2019, 37 (Suppl. 120), 57-63.

37. Robinson, W.H.; Lepus, C.M.; Wang, Q.; Raghu, H.; Mao, R.; Lindstrom, T.M.; Sokolove, J. Low-grade inflammation as a key mediator of the pathogenesis of osteoarthritis. Nat. Rev. Rheumatol. 2016, 12, 580-592. [CrossRef]

38. Xue, E.X.; Lin, J.P.; Zhang, Y.; Sheng, S.R.; Liu, H.X.; Zhou, Y.L.; Xu, H. Pterostilbene inhibits inflammation and ROS production in chondrocytes by activating Nrf2 pathway. Oncotarget 2017, 8, 41988-42000. [CrossRef]

39. Shateri, H.; Ranjbar, A.; Kheiripour, N.; Ghasemi, H.; Pourfarjam, Y.; Habibitabar, E.; Gholami, H.; Moridi, H. Tempol improves oxidant/antioxidant parameters in testicular tissues of diabetic rats. Life Sci. 2019, 221, 65-71. [CrossRef] [PubMed]

40. Zhao, H.; Zhao, Y.; Li, X.; Xu, L.; Jiang, F.; Hou, W.; Dong, L.; Cao, J. Effects of Antioxidant Tempol on Systematic Inflammation and Endothelial Apoptosis in Emphysematous Rats Exposed to Intermittent Hypoxia. Yonsei Med. J. 2018, 59, 1079-1087. [CrossRef]

41. Afjal, M.A.; Abdi, S.H.; Sharma, S.; Ahmad, S.; Fatima, M.; Dabeer, S.; Akhter, J.; Raisuddin, S. Anti-inflammatory role of tempol (4-hydroxy-2,2,6,6-tetramethylpiperidin-1-oxyl) in nephroprotection. Hum. Exp. Toxicol. 2019, 38, 713-723. [CrossRef] [PubMed]

42. Johnson, C.I.; Argyle, D.J.; Clements, D.N. In vitro models for the study of osteoarthritis. Vet. J. 2016, 209, 40-49. [CrossRef] [PubMed]

43. Xie, J.; Huang, Z.; Yu, X.; Zhou, L.; Pei, F. Clinical implications of macrophage dysfunction in the development of osteoarthritis of the knee. Cytokine Growth Factor Rev. 2019, 46, 36-44. [CrossRef]

44. Cai, S.; Ming, B.; Ye, C.; Lin, S.; Hu, P.; Tang, J.; Zheng, F.; Dong, L. Similar Transition Processes in Synovial Fibroblasts from Rheumatoid Arthritis and Osteoarthritis: A Single-Cell Study. J. Immunol. Res. 2019, 2019, 4080735. [CrossRef] [PubMed]

45. Goldring, M.B.; Otero, M. Inflammation in osteoarthritis. Curr. Opin. Rheumatol. 2011, 23, 471-478. [CrossRef] [PubMed]

46. Kapoor, M.; Martel-Pelletier, J.; Lajeunesse, D.; Pelletier, J.P.; Fahmi, H. Role of proinflammatory cytokines in the pathophysiology of osteoarthritis. Nat. Rev. Rheumatol. 2011, 7, 33-42. [CrossRef] [PubMed]

47. Wang, T.; He, C. Pro-inflammatory cytokines: The link between obesity and osteoarthritis. Cytokine Growth Factor Rev. 2018, 44, 38-50. [CrossRef]

48. Zeng, G.Q.; Chen, A.B.; Li, W.; Song, J.H.; Gao, C.Y. High MMP-1, MMP-2, and MMP-9 protein levels in osteoarthritis. Genet. Mol. Res. 2015, 14, 14811-14822. [CrossRef]

49. Rose, B.J.; Kooyman, D.L. A Tale of Two Joints: The Role of Matrix Metalloproteases in Cartilage Biology. Dis. Markers 2016, 2016, 4895050. [CrossRef] 